\title{
ESA CAÍDA DE ALTAZOR QUE PERMANECE EN EL TIEMPO
}

\author{
Altazor: A fall that lingers in time
}

\author{
María Inés Zaldívar*
}

\begin{abstract}
RESUMEN
Este texto presenta una posible lectura de Altazor de Vicente Huidobro publicado inicialmente en 1931, poema fundador e ineludible de nuestro canon literario. Esta lectura personal se inscribe como una más dentro de la historia de la recepción crítica que ha tenido la caída altazoriana a través del tiempo. Esta aproximación toma como hilo conductor la conciencia que tiene el hablante del fenómeno de la lengua y de su dificultad para significar en poesía.
\end{abstract}

Palabras clave: poesía chilena, Vicente Huidobro, Altazor, lectura crítica, lenguaje poético.

\begin{abstract}
This article presents a posible reading of Altazor, by Chilean writer Vicente Huidobro, a poem which was initially published in 1931, becoming a fundamental and founding work in the Chilean literary canon. This personal reading inscribes itself into the critical reception which has devoted its attention to the Altazorian fall over the years. This approach takes as its central concern the consciousness that the speaker in the poem possesses of the phenomenon of language and its difficulty in granting meaning to poetry.

Keywords: Chilean Poetry, Vicente Huidobro, Altazor, Critical Reading, Poetic Language.

\footnotetext{
* Directora Extensión y Educación Continua, Académica de la Facultad de Letras, Pontificia Universidad Católica de Chile. Santiago, Chile. Correo electrónico: mizaldiv@uc.cl

Artículo recibido el 01 de junio de 2017. Aceptado el 28 de agosto de 2017.
} 
La presente relectura de Altazor de Vicente Huidobro se inscribe y se reconoce como parte de una genealogía de otras tantas lecturas tales como las de Cedomil Goic, Jaime Concha, Ana Pizarro, Óscar Hahn y Federico Shopff, y ojalá lo sea también de muchas más que la sucedan. Esta actual mirada pretende incorporarse como otro eslabón de la cadena que va conectando este fundador e ineludible texto de nuestro canon poético, desde su momento de publicación en 1931, hasta el día de hoy. Por cierto es una posible lectura personal, parcial e inconclusa que, como sabemos, también responde, en parte indeterminada, a mi propia subjetividad construida a la vera de cercanías, afinidades, miedos y obsesiones.

Altazor, sujeto que canta, llora y clama mientras cae al vacío lentamente en un paracaídas, con un movimiento "regido por una cosmología negativa que arrastra todo lo existente hacia su aniquilamiento y muerte, por una ley de gravitación universal poderosa y mortal, inescapablemente destructora"(p. 109) ${ }^{1}$, al decir de Cedomil Goic es, al mismo tiempo, un sujeto que propone orientar y sostener sentimentalmente la constitución de nuevas imágenes, según Federico Schpof; este planteará su lectura como respuesta a dos grandes preguntas: “¿Por qué (el sujeto propone, necesita anhela) el ser y no más bien la nada?” y la otra, por donde se encaminará la mía, "referida a los límites y alcances de la poesía"(p. 1492)2. A propósito de esta nueva construcción de imágenes, mencionada por Schopf, Jaime Concha aporta una luminadora hipótesis al plantear que estas imágenes conformarían en el texto una constelación cuya matriz central se aglutinará en torno a la figura de la mujer, dando origen a tres movimientos fundamentales: la soledad y la angustia; el afán de eternidad; y la presencia viva de la creación poética ${ }^{3}$. Y este sujeto Altazor, que cristaliza en palabras a principios de los ańos treinta del siglo pasado "la vida del hombre primitivo vuelta hacia los astros, guiándose por ellos, interpretándolos y forjando mil leyendas, se une a la del hombre del siglo veinte, para quien el espacio sideral es el aerolito, el meteoro y el avión”, como bien dijo Ana Pizarró ${ }^{4}$

La lectura de Altazor nos devela entonces a un hablante que recorrerá, en caída libre, durante un prefacio y siete cantos convertido, o más precisamente trasvestido, ya sea en aviador, "pastor de aeroplanos", "orquesta trágica”, gran poeta, pájaro, mago, o ángel (el que puede transformarse tanto en uno caído,

\footnotetext{
${ }^{1}$ Cfr. «Altazor, de Vicente Huidobro» Historia y critica de la Literatura Hispanoamericana 3, Época Contemporánea. Barcelona: Editorial Crítica, 1980, pp. 109-113.

${ }^{2}$ Cfr. «Lectura de Altazor» en Vicente Huidobro. Obra poética. Edición crítica, Archivos 45, 2003, pp. 1491-1506.

${ }^{3}$ Cfr. Huidobro, Vicente. Madrid: Ediciones Júcar, 1980.

${ }^{4}$ Cfr. "El creacionismo de Vicente Huidobro y sus orígenes", Revista Mapocho, Santiago de Chile, vol. 18, 1969. Disponible en: http://www.vicentehuidobro.uchile.cl/ensayos_ana_pizarro.html.
} 
como en otro salvaje, o loco), describiendo entre los astros una estela que dibujaría una especie de viaje funerario de la palabra poética. Lo hará, según Óscar Hahn, emulando al personaje Nietche, pero como "un loco apócrifo". Uno que "quiere rodearse del aura excéntrica que proporciona la demencia, pero conservando al mismo tiempo el lugar que los cuerdos se reservan en la sociedad"(p. 17)

Este Altazor será quien una tarde coge su paracaídas - "la única rosa perfumada de la atmósfera, la rosa de la muerte" (Prefacio, 735) ${ }^{6}$ - y, acomodado en los arneses bajo su amplio globo, inicia ese solitario y angustioso descenso "de sueño en sueño por los espacios de la muerte"(Prefacio, 731). Nos contará de su nacimiento "a los treinta y tres ańos, el día de la muerte de Cristo" (Prefacio, 731); de su padre, quien "era ciego y sus manos más admirables que la noche" (Prefacio, 731); de su madre - sin igual- quien, entre otras cosas, "hablaba como la aurora y como los dirigibles que van a caer" y "bordaba lágrimas desiertas en los primeros arcoíris" (Prefacio, 731). Luego dará cuenta de sus primeros encuentros; el con ese pájaro que se bebe las gotas de rocío de sus cabellos, le lanza tres miradas y media, y se aleja diciéndole "Adiós" mientras agita "su pańuelo soberbio" (Prefacio, 731); también el que sostiene con un "precioso aeroplano, lleno de escamas y caracoles" (Prefacio, 731), quien busca "un rincón del cielo para guarecerse de la lluvia" (Prefacio, 731); y, si no uno que suponga contacto visual, mas sí uno potente, auditivo, seremos testigos del encuentro con el "Creador, sin nombre, que es un simple hueco en el vacío, hermoso como un ombligo" (Prefacio, 731).

La voz del Creador recitará al viajero la narración de los pasos de su creación: la del mar con sus olas que "irán siempre pegadas como los sellos a la tarjetas postales" (Prefacio,732); a la de la luz que permitirá "coser los días uno a uno" (Prefacio, 732); el advenimiento tanto de la tierra con su geografía de relieves como al otro que se inscribe en "las líneas de la mano" (Prefacio, 732). Y, entonces, fruto de la sed "(a causa de la hidrografía)" (732), esa voz del Creador evocará la necesidad que tuvo de beber cognac (que no agua ni vulgar bebestible) para saciar su sed, y contará de su creación de "la boca y los labios de la boca para aprisionar las sonrisas inequívocas y los dientes de la boca para vigilar las groserías que nos vienen de la boca" (Prefacio, 732). De ahí, y sin mediar un paso, dará cuenta del alumbramiento de "la lengua de la boca", esa que por desgracia, "desviaron de su rol, haciéndola aprender a hablar... a ella, ella, la bella nadadora, desviada para

\footnotetext{
${ }^{5}$ Cfr. "Prólogo" en Altazor. Edición facsimilar, Santiago de Chile: Editorial Universitaria, 1991, pp. 7-24.

${ }^{6}$ Todas las citas del poema serán tomadas de Vicente Huidobro Obra Poética. Edición Crítica, Cedomil Goic, coordinador. 1ª edición. Madrid; Barcelona; La Habana; Lisboa; París; México; Buenos Aires; São Paulo; Lima; Guatemala; San José; Caracas: ALLCA XX, (Colección Archivos, 45) 2003, pp. 729-808.
} 
siempre de su rol acuático y puramente acariciador" (Prefacio, 732). Y será en el marco de esta puesta en escena, después de todo lo anteriormente descrito, que su "paracaídas empieza a caer vertiginosamente, [pues] tal es la fuerza de atracción de la muerte y del sepulcro abierto" (Prefacio, 732).

Enfrentada a este ejercicio escritural, con una rica historia de lecturas previas, podría agregar en esta ocasión que percibo en el Altazor de Vicente Huidobro, tomando como hilo conductor esta desnaturalización de la lengua en su función primaria, y su forzamiento hacia otras funciones ya no tan gratuitas y gozosas, un monumental lamento sobre la pérdida de ese paraíso original de la sagrada materia, que derivará en una alucinada y radical conciencia del límite, ("Con dolor de límites constantes y vergüenza de ángel estropeado”, dirá Altazor en el Canto I, 742), de los límites de lo humano y cuasi divinos en su autopercepción, fijados desde el nacimiento a través del epítome de todos los límites, la conciencia de la muerte, de aquella que "se acerca a la tierra como el globo que cae" (Prefacio, 731). Paso a compartir mis reflexiones.

Dentro de este contexto inicial de recuerdos, señalamientos y presencias del cayente, es que me interesa retomar el hilo de la madeja de este viaje alucinado (quizá amorfinado), que va desde "el Equinoccio, bajo las hortensias y los aeroplanos del calor" (Prefacio, 731), hasta la "Flor y noche/ Con su estatua/ Cristal muerte" (Canto VI, 806). Más precisamente, me interesará establecer una relación entre la caída de Altazor y esa boca impregnada de cognac dentro de la cual la lengua, en vez de permitírsele solo disfrutar del placer y el letargo acariciante de la flotación en líquidos varios, se le enseña y fuerza a la palabra que, en este caso, no se relaciona solo con el forzamiento al lenguaje articulado a través del habla sino que, más a contrapelo, al del lenguaje escrito y, mucho más aún, al del lenguaje poético impreso sobre la hoja de papel: doble, no, triple expulsión del paraíso. Porque el monólogo altazoriano explícita e implícitamente hablará todo el tiempo de poesía y de su construcción, de su creación. Dirá que "Los verdaderos poemas son incendios" (Prefacio, 732) que irremediablemente se propagan para ver sus "estremecimientos de dolor o de agonía"(Prefacio, 732), que "un poema es una cosa que será", o que más bien "una cosa que nunca es, pero que debiera ser" (Prefacio, 732) que "se debe escribir en una lengua que no sea materna” (Prefacio, 732) aunque es, en realidad, "una cosa que nunca ha sido, que nunca podrá ser" (Prefacio, 732).

Altazor, el viajero protagonista, es ese que está "Encerrado en la jaula de su destino" y que "En vano [se] aferr[a] a los barrotes de la evasión" (Canto I, 737). Es ese aviador camaleónico que en su recorrido buscará traspasar la barrera de lo humano tanto hacia lo pajarístico como hacia lo esotérico, lo angelístico, y con derechas pretensiones hacia lo divino eternal. Y Altazor es también a ratos un urgido y ansioso sujeto, como el conejo blanco de ojos rosados, con reloj de bolsillo, que aparece frente a Alicia, repitiendo “¡Voy a llegar tarde!”, y cuya presencia la arrastra 
a ese otro viaje, madriguera adentro, hacia el fondo de la tierra ${ }^{7}$. Nuestro viajero en cambio, mientras se desplaza por los aires y en caída libre, dirá: "No hay tiempo que perder" (Canto IV, 770), puesto que "A la hora del naufragio ambiguo/ Yo mido paso a paso el infinito [.... mientras ] El mar quiere vencer/ y por lo tanto no hay tiempo que perder" (Canto IV, 770-771) ya que, quizás, por fin, "Más allá del último horizonte/ Se verá lo que hay que ver" (Canto IV, 771).

Dentro de este escenario, percibo que el hablante del poema esgrime una constante y porfiada búsqueda de utilización de la palabra, y me voy a permitir utilizar una imagen que me viene a la mente, y es que pienso en Josefina Ludmer y sus "tretas del débil", cuando se refiere a Sor Juana Inés de la Cruz, develando sus estrategias y triquińuelas para hacerse de la palabra y establecer una voz frente a la autoridad desde la estructurada indefensión que habita. Según Ludmer, en el caso de la Respuesta de Juana Inés de la Cruz a sor Filotea, que es el texto analizado bajo este prisma, hay dos verbos claves: saber y decir, pues ambos constituirían los campos enfrentados para una mujer. Las tretas, entonces, se desprenderían del manejo que se hace de ellos: "en primer lugar, separación del campo del saber del campo del decir; en segundo lugar, reorganización del campo del saber en función del no decir (callar) (p. 48)" ${ }^{8}$. Guardando las proporciones, Altazor, quien incursiona abiertamente a veces lúdica y gimnásticamente con la palabra fungiendo ser ese primigenio creador sin nombre, ese simple hueco en el vacío que es hermoso como un ombligo, tiene sus tretas, sus tretas de débil: se trasviste de niño o de loco delirante y, aunque sabe lo que quiere, no lo dice comprensivamente sino lo calla para la lengua articulada. Lo oculta tras cadenas de letras y palabras sonoras que no tienen existencia legal dentro del diccionario de la lengua castellana. Ejerce como creador de una palabra alucinada que juega e insiste decir callando, en el intento de crear nuevos caminos que permitan romper barreras, abrir rendijas, no para acceder al mundo de la institucionalidad masculina, como en el caso de sor Juana (pues en realidad por condición social y género sí forma parte de ella), sino para decir lo indecible y con ello volver a contactarse y disfrutar la perfección de una materialidad tanto inexpugnable, como eterna e inmutable. Así las cosas, aunque en el poema el hablante señala explícitamente al inicio del Canto V que "Aquí comienza el campo inexplorado" (782), ya desde el Canto IV, Altazor, frente al inexpugnable mundo cotidiano empieza - para emborrachar la perdiz (o en este

\footnotetext{
${ }^{7}$ Por cierto me estoy refiriendo a Alicia y el pais de las maravillas de Lewis Carroll.

"There was nothing so very remarkable in that; nor did Alice think it so very much out of the way to hear the Rabbit say to itself, 'Oh dear! Oh dear! I shall be late!'” (p. 17). Cfr, Alice's Adventures in Wonderland, Chapter I, Down the Rabbit Hole.

${ }^{8}$ Cfr. "Tretas Del débil" en Patricia González y Eliana Ortega (eds.). La sartén por el mango. Encuentro de escritoras latinoamericanas. Río Piedras: Ediciones Huracán, 1984, pp. 47-54.
} 
caso específico la golondrina, cual niño travieso (mimado y desesperado) - con la utilización de juegos de palabras que nombran sincopadamente un abanico de posibilidades para hacer frente a esta realidad inasimilable a través de su arte denominativo. Un par de ejemplos:

Al horitaña de la montazonte
La violondrina y el goloncelo
Descolgada esta mañana de la lunala
Se acerca a todo galope
Ya viene viene la golondrina
Ya viene viene la golonfina
Ya viene la golontrina
Ya viene la goloncima
Viene la golonchina
Viene la golonclima
Ya viene la golonrima
Ya viene la golonrisa
La golonniña
La golongira
La golonlira
La golonbrisa
La golonchilla
Ya viene la golondía
Y la noche encoge sus uńas como el leopardo (Canto IV, 775-776).

O este en este otro fragmento, el del molino, que puede leerse en su persistencia por hacer como que: "Jugamos fuera del tiempo/ Y juega con nosotros el molino del viento [...]" (Canto V, 789), pero que luego de ciento noventa y un versos que lo adjetivan y juegan con él, termina siendo un "Molino truculento"(794). Lo es tal puesto: "Que teje las noches y las mañanas/ Que hila las nieblas de ultratumba/ Molino de aspavientos y del viento en aspas/ El paisaje se llena de tus locuras" (Canto V, 794-795). Me aventuro a postular que veo en este tipo de discurso que sabe y calla paradójicamente vociferando, como cabezazos contra el muro, a veces torpes, otras con mayor estilo, pero cabezazos que del juego pasan al dolor y que progresivamente van aturdiendo y desintegrando al escribidor y su palabra contra el suelo, acomodando su aullido sobre la superficie de la tierra, pero sin penetrarla, para solo deletrear finalmente un "Ai ai ai ai i i i o ia"(Canto VI, 808).

Esta búsqueda se realiza, además de utilizando las tretas anteriores, a través de una palabra que nombra personas y cosas tanto en su belleza como en su fragilidad. Es el canto a la belleza y deseo de fusión con la mujer, ya sea la madre biológica, esa "con ojos de bandera y ojos llenos de navíos lejanos" (Prefacio, 731); 
o la Virgen, aquella "sin mancha de tinta humana" (Prefacio, 733) y escrita con mayúscula, venerada en un casi impúdico marianismo religioso, cuya mirada es "un alambre en el horizonte para el descanso de las golondrinas" (Prefacio, 733); y por cierto, con largueza, por la enamorada, la amada que permanece, salvadora, indispensable, y poblando de bellas imágenes el Canto II:

$[\ldots]$

Mí alegría es oír el ruido del viento en tus cabellos

(Reconozco ese ruido desde lejos)

Cuando las barcas zozobran y el río arrastra troncos de árbol

Eres una lámpara de carne en la tormenta

Con los cabellos a todo viento

Tus cabellos donde el sol va a buscar sus mejores sueños

Mi alegría es mirarte solitaria en el diván del mundo

Como la mano de una princesa sońolienta

Con tus ojos que evocan un piano de olores

Una bebida de paroxismos

Una flor que está dejando de perfumar

Tus ojos hipnotizan la soledad

Como la rueda que sigue girando después de la catástrofe (Canto II, 761-762)

$[\ldots]$

Nada se compara a esa leyenda de semillas que deja tu presencia

A esa voz que busca un astro muerto que volver a la vida

Tu voz hace un imperio en el espacio

$Y$ esa mano que se levanta en ti como si fuera a colgar soles en el aire

$Y$ ese mirar que escribe mundos en el infinito

Y esa cabeza que se dobla para escuchar un murmullo en la eternidad

Y ese pie que es la fiesta de los caminos encadenados

Y esos párpados donde vienen a vararse las centellas del éter

Y ese beso que hincha la proa de tus labios

Y esa sonrisa como un estandarte al frente de tu vida

$\mathrm{Y}$ ese secreto que dirige las mareas de tu pecho

Dormido a la sombra de tus senos

Si tú murieras

Las estrellas a pesar de su lámpara encendida

Perderían el camino

¿Qué sería del universo? (Canto II, 762-763).

En Altazor presenciamos el drama de esa Palabra que quisiera ser Lengua, y que es manipulada en manos de ese pequeño dios aunque sabe y reconoce con dolorosa conciencia que solo: 
Manicura de la lengua es el poeta

Mas no el mago que apaga y enciende

Palabras estelares y cerezas de adioses vagabundos

Muy lejos de las manos de la tierra

Y todo lo que se dice es por él inventado

Cosas que pasan fuera del mundo cotidiano

Matemos al poeta que nos tiene saturados (Canto III, 766).

De una u otra manera, en el texto presenciamos la fatalidad de ese dolor conocido, que tan bien había cantado Rubén Darío veintiséis años atrás, "pues no hay dolor más grande que el dolor de ser vivo,/ ni mayor pesadumbre que la vida consciente", mientras son "Dichoso el árbol, que es apenas sensitivo,/ y más la

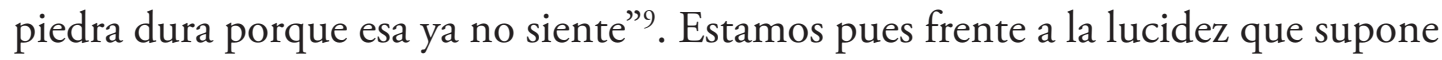
la vida consciente y al desgarro que acarrea el develamiento de la fragilidad de este constructor y todos los constructores y constructoras de universos verbales. $\mathrm{Su}$ fragilidad y su grandeza radican en que, aunque la palabra poética puede nombrarlo todo, representarlo todo, esta no podrá nunca ser otra cosa de lo que es, una posible representación, otro eslabón más de esta cadena de desplazamientos del significante, como diría Derridá. Y, más que debido a la pericia o impericia del creador, la flaqueza e imposibilidad de esa vuelta a la fusión original, proviene de que la palabra poética, esa que sigue "cultivando en el cerebro las tierras del error", y que permanecerá, "sin que se derrumben las vigas del cerebro"(Canto I, 741), está en las afueras, dentro de su sellada e inexpugnable materialidad. Estaremos resignados, entonces, a movernos en un universo "Lleno de zafiros probables/ De manos de sonámbulos/ De entierros aéreos/ Conmovedores como el sueño de los enanos" (Canto V, 782).

La palabra poética podrá nombrar las cerezas más fragantes, sabrosas y coloridas, pero solo alcanzará a hacerle guiños, quizás a acariciarlas mentalmente, con suerte a fundirse con su sabor, olor y materialidad, fruto de la maestría con que el pequeño dios las representa sobre la página, pero luego de ese instante de arrobo mental, surgirá el hambre de su dulzura que solo se saciaría con el mordisco y la pulpa dentro de la boca. Así, como el desanudamiento de los cuerpos enamorados, palabra y objeto o sujeto representado, volverán a su indivisible individualidad, a su redil, a su porción material intransferible, ya que aunque "Tus ojos [que] hipnotizan la soledad" pueden ser bellamente escritos "como rueda que sigue girando después de la catástrofe”, nunca podrán sonreír o llorar con saliva o lágrimas saladas.

Esta caída de Altazor dibuja el intento a través de la palabra de una entrada o una salida a la materia, expresada en los progenitores, la mujer, la modernidad y

${ }_{9}^{9}$ Poema "Lo Fatal" de Rubén Darío, perteneciente a Cantos de vida y esperanza, 1905. 
sus innumerables aparatos, en las creencias que se niegan y sin embargo se nombran con insistencia casi como letanías, como paracaídas auxiliares frente al abismo de la nada. Y se suma pienso yo, el drama supremo, el de estar expuesto, señalado, frente al todo, irremediablemente indefenso por estas afueras - "siento un telescopio que me apunta como un revólver (Canto I, 736)"-, y no poder salirse de sí mismo para mirarse, dimensionarse, poseerse, protegerse y amarse eternamente. En este marco resuenan formidables las palabras de Altazor desafiando a la muerte: "Muera la muerte infiltrada de rapsodias langurosas" (Canto I, 742), como lo hiciera siglos y siglos atrás Juan Ruiz, el Arcipreste de Hita, en su Libro del buen amor (13301343), frente a la muerte de su indispensable Urraca:

¡Ay Muerte! ¡Muerta seas, muerta, e mal andante!
Mataste a mi vieja, ¡matases a mí ante!
Enemiga del mundo, que non as semejante,
de tu memoria amarga non sé quien non se espante ${ }^{10}$.

Percibo en todo el texto de Altazor una búsqueda radical hacia estadios crecientes de conciencia para asimilar y poseer, sin mediación, el sabor de esa inaccesible realidad. Esta conciencia de desconexión produce en el cayente una desubicación espacial y temporal del lugar y la hora en que se habita; produce vértigo frente a lo silencioso y reprimido, y pánico frente a la pérdida del control, a la locura que no es otra cosa, pienso yo, que la ruptura del cordón umbilical que nos conecta con el ser. Así las cosas, se da en el poema huidobriano la siguiente paradoja: la palabra, que es el arma, la materia prima, la riqueza, el oro, la divisa con mayor plusvalía en el mercado del creador, puede a su vez convertirse en su prisión, en su castigo, en su cepo. Esta afirmación me mueve a pensar que este poema está problematizando la afirmación que recorre nuestra poesía y la poesía en general, en el sentido de que esta salva la existencia, de que se está vivo porque se escribe como dijo Enrique Lihn, o que salva de morir como un perro, al decir de Manuel Silva Acevedo, pero entrar en esa materia ameritaría una reflexión mayor, que queda pendiente.

Quisiera concluir señalando que Altazor de Vicente Huidobro podría apreciarse como la estampa, más bien diríamos hoy el vídeo de una caída, caída hacia la desintegración, no solo hacia la desintegración de la palabra poética, sino del yo, del ser que se disuelve en un vacío del abajo que conduce a la nada. Sin embargo, podría percibirse desde la mirada de ese abajo, desde su contracara, aquella que recibe la caída, que quizás este tránsito desde el ser a la nada, podría inaugurar una nueva entrada (al parecer no percibida por el descendente) que

${ }^{10}$ Cfr. en Arcipreste de Hita, Libro del Buen Amor, coplas 1520 a 1523. 
no se define en términos espaciotemporales, una que conduce hacia un estado de conciencia ininteligible desde la humanidad, como al parecer William Blake avizoró $^{11}$. Si quisiéramos considerar la existencia de un nuevo estado de cosas si se abrieran esas puertas de la percepción, quién sabe a qué entrada fascinante y aterradora nos conducirían. En todo caso, en Altazor sí está inscrita desde el inicio una leve esperanza, quien sabe si amortiguadora del golpe, que alienta a atreverse a caer hacia abajo y hacia adentro, en busca de "una luz sin noche":

Déjate caer sin parar tu caída sin miedo al fondo de la sombra sin miedo al enigma de ti mismo Acaso encuentres una luz sin noche Perdida en las grietas de los precipicios (Canto I, 737).

\section{REFERENCIAS}

Blake, William. The Marriage of heaven and hell (1793). Library of Congress. BOSTON JOHN W. LUCE AND COMPANY 1906. Disponible en: https://ia600202. us.archive.org/8/items/marriageofheaven00blak/marriageofheaven00blak.pdf. [Consultado el 10 de enero de 2017].

Carroll, Lewis. Alic's Adventures in Wonderland, Chapter I, "Down the Rabbit Hole". En The Complete Illustrated Works of Lewis Carroll. London: Reed International Books Ltd, 1996.

Concha, Jaime. Vicente Huidobro. Madrid: Ediciones Júcar, 1980.

Darío Rubén. Cantos de vida y esperanza en Poesía. 2a Edición. Prólogo de Ángel Rama. En Ernesto Mejía Sánchez (Ed.). Caracas: Biblioteca Ayacucho, 1985.

Huidobro, Vicente. Altazor. En Vicente Huidobro Obra Poética. Edición Crítica, Cedomil Goic (Coord.), 1a edición. Madrid; Barcelona; La Habana; Lisboa; París; México; Buenos Aires; Sao Paulo; Lima; Guatemala; San José; Caracas: ALLCA XX, (Colección Archivos, 45), (2003): 729-808.

\footnotetext{
${ }^{11}$ If the doors of perception were cleansed, every thing would appear to man as it is, infinite. For man has closed himself up, Till he sees all things through narrow chinks of his cavern. En The Marriage of heaven and hell (1793). Poema de William Blake que, como sabemos, fue tomado por el cantante, compositor y poeta estadounidense Jim Morrison (1943-1971), para dar nombre a su grupo musical The Doors.
} 
Goic, Cedomil. «Altazor, de Vicente Huidobro» Historia y crítica de la Literatura Hispanoamericana 3 Época Contemporánea. Barcelona: Editorial Crítica, (1980): 109-113.

Hahn, Óscar. «Altazor, el canon de la vanguardia y el recuerdo de otras vidas más altas" Hispamérica 20:59 (1991): 11-21. [Reproducido como "Prólogo" a Altazor. Edición facsimilar, Santiago, Chile: Editorial Universitaria, 1991. 7-24].

Ludmer, Josefina. "Tretas Del débil" en Patricia González y Eliana Ortega (eds.). La sartén por el mango. Encuentro de escritoras latinoamericanas. Río Piedras: Ediciones Huracán, 1984.

Pizarro, Ana. "El creacionismo de Vicente Huidobro y sus orígenes", Revista Mapocho, Santiago de Chile, V, 18 (verano, de 1969). Disponible en: http:// www.vicentehuidobro.uchile.cl/ensayos_ana_pizarro.htm [Consultado el 05 de enero de 2017].

Ruiz, Juan, Arcipreste de Hita. Libro de buen amor. Edición de Alberto Blecua. Madrid: Cátedra, 1998.

Schpof, Federico. «Lectura de Altazon» Vicente Huidobro. Obra poética. Edición crítica, Archivos 45, (2003): 1491-1506. 